\title{
Strategies for Safety
}

Imagine that you are the leader of a healthcare unit or organisation. You are concerned about safety but you have (as always) limited time and resources. You plan a programme lasting 1 year initially and perhaps extending to 5 years.

- What should you do to improve safety?

- What safety strategies are available to you?

- How can these strategies be most effectively combined?

You might first review safety standards in your organisation and the evidence for safety improvement. From this you would probably conclude, as we have argued earlier, that there are many lapses from basic standards and that the most critical task is to improve adherence to basic safety critical procedures. This is of course easier said than done but it is the basis of most healthcare safety interventions whether this is reducing infection, improving risk assessment, avoiding wrong site surgery or improving medication safety. By this point in the book however you will have realised the near impossibility of always providing optimal care which corresponds with standards in many, if not most, settings in healthcare. Adherence to standards provides an essential foundation but not a complete vision. We may have to think a little more broadly.

\section{What Options Do We Have for Improving Safety?}

We should be wary of modelling all future safety interventions on our most visible successes. In some highly standardised areas, such as radiotherapy or management of blood products, a combination of automation and highly standardised procedures combine to deliver genuinely ultra-safe systems. However, at the other extreme, consider the care of a patient with psychosis in the community. We cannot, and should not, enforce standards and procedures in care that patients and families provide. The management of risk in such a setting clearly requires a different approach 
based more on anticipation and detection of incipient problems and a rapid response. We have to accept and value greater autonomy and, with this greater freedom, comes greater risk. This means that safety strategies need to rely less on rules and standards and more on the detection of problems and a rapid response to them.

In the remainder of this chapter we outline the main strategies for improving safety in healthcare that can be used by our imaginary clinical leader or manager. Our hope is that providing a high level architecture of safety strategies will support frontline leaders and organisations in devising an effective safety programme. Rather than adopting piecemeal solutions we believe that we need to first articulate a high level vision of what strategies are available and how they might be employed in each setting. As we will see some strategies are most useful in highly standardised areas of work while others come to the fore in more fluid and dynamic environments. None of them in isolation necessarily provide a high level of patient safety. The aim is to find a blend of strategies and interventions appropriate to the context and the organisation.

\section{Five Safety Strategies}

We outline five broad strategies (Box 6.1) each of which is associated with a family of interventions. The strategies are, we believe, applicable at all levels of the healthcare system from the frontline to regulation and governance of the system. Two of the strategies we discuss aim to optimise the care provided to the patient. The other approaches are focused on the management of risk and the avoidance of harm.

\section{Box 6.1 Five Safety Strategies}

Safety as best practice: aspire to standards - Reducing specific harms and improving clinical processes

Improving healthcare processes and system - Intervening to support individuals and teams, improve working conditions and organisational practices

Risk control - Placing restrictions on performance, demand or working conditions

Improving capacity for monitoring, adaptation and response.

Mitigation - Planning for potential harm and recovery.

The first two strategies approaches aim, broadly speaking, to achieve safety by optimising care for the patient. In a sense safety and quality and equated; the aim is to provide care at levels 1 and 2. Within this general approach we distinguish focal safety programmes aimed at specific harms or specific clinical processes (Safety as best practice) and more general attempts to improve work systems and processes across a number of clinical settings (Improving the system). These approaches are well described in the patient safety literature and we will only briefly summarise the main features here as our primary purpose is to draw attention to other important and complementary approaches. 
Optimisation of processes and systems is indeed optimal if it can be made to work. The difficulty is that in the real world optimal care is usually not achievable for at least some of the time. Once there is evidence of a substantial departure from best practice then the question becomes how best to manage those departures and the associated risk. The remaining three approaches are risk management strategies: risk control; monitoring, adaptation and response; and mitigation. Optimisation strategies improve efficiency and other aspects of quality as much as they improve safety. In contrast risk control, adaptation and recovery strategies are most concerned with improving safety.

Safety problems are also sometimes resolved because of the introduction of a completely new way of investigating or treating an illness. The development and rapid adoption of laparoscopic surgery for instance means that patients no longer have large wounds from major incisions, are less vulnerable to infections and have a much shorter hospital stay. Reduction of infection is a major safety target but was here achieved indirectly by a major surgical innovation. While we recognise that innovation often improves safety we do not consider it as a safety strategy, in the sense of a plan that can be implemented relatively quickly, because major innovations usually occur over long time periods and can only be implemented once they have been tried and tested.

\section{Strategy I: Safety as Best Practice}

The most dramatic safety improvements so far demonstrated have been those with a strong focus on a core clinical issue or a specific clinical process. They may be focussed on the reduction of a specific form of harm, such as falls or central line infections, or increasing the reliability of specific clinical processes such as pre-operative checks. We originally conceptualised this approach as 'aspiring to standards' as we regard basic standards and procedures as the foundation of safe systems, though we recognise that for an individual patient there is a great deal more to optimal care than achieving standards. In our terms 'best practice' suggests that a team or organisation aims and believes that they can provide care at levels 1 and 2 (Table 6.1)

A recent review of the patient safety literature (Shekelle et al. 2011) found only ten interventions that could be currently recommended for implementation; almost

Table 6.1 Safety as best practice: aspire to standards

\begin{tabular}{|c|c|}
\hline Interventions & Examples \\
\hline \multirow{4}{*}{$\begin{array}{l}\text { Focal safety programme: reduction } \\
\text { of harm }\end{array}$} & Interventions to reduce central line infections \\
\hline & Inpatient falls reduction programmes \\
\hline & Interventions to reduce urinary catheter use and infection \\
\hline & Interventions to reduce pressure ulcers \\
\hline \multirow{3}{*}{$\begin{array}{l}\text { Improved reliability of targeted } \\
\text { processes }\end{array}$} & WHO Surgical safety and other checklists \\
\hline & Medication reconciliation \\
\hline & Care bundles for ventilator associated pneumonia \\
\hline
\end{tabular}


all of them would, in our terms, be described as focal safety interventions. The essential idea is that complying with proven evidence and standards will produce optimal quality and safety. Many patients come to harm because established, scientifically based standards of practice are not reliably followed. Safety interventions of this kind first marshal the scientific evidence, then identify the core practices and endeavour to reliably bring these practices to patient care.

\section{Box 6.2 Improving Safety by Achieving Best Clinical Practice}

- Explicitly describe the theory behind the chosen intervention or provide an explicit logic model for why this patient safety practice should work

- Describe the patient safety practice in sufficient detail that it can be replicated, including the expected effect on staff roles

- Detail the implementation process, the actual effects on staff roles, and how the implementation or intervention changed over time

- Assess the effect of the patient safety practice on outcomes and possible unexpected effects, including data on costs when available

- For studies with multiple intervention sites, assess the influence of context on the effectiveness of intervention and implementation

Adapted from Shekelle et al. (2011)

It sounds simple; one identifies a standard set of safety critical procedures and supports the staff to follow them. However, in practice these are always complex, multifaceted interventions encompassing techniques, organisation and leadership (Pronovost et al. 2008). These interventions are of course far from simple and only succeed because of a sophisticated approach to clinical engagement and implementation (Box 6.2). The reduction of central line infections for instance required changes to the organisation of care, the equipment used, simplification of guidelines, engaging local multidisciplinary teams, a staff education programme, technical measurement support and a major programme of implementation.

\section{Strategy II: Improvement of Work Processes and Systems}

Accident and incident analysis and other methods reveal a great deal about the vulnerabilities in our systems and show us the range of factors which need to be addressed if we are to design a safer, high quality healthcare system. Thoughtful analyses of serious incidents reveal a range of contributory factors relating to the patient, task and technology, staff, team, working environment, organisational and institutional environmental factors (Vincent et al. 1998). This is the classic territory of the organisational accident in which immediate errors and failures are identified which are strongly influenced by wider organisational factors. These same factors 
Table 6.2 Improvement of healthcare system and processes

\begin{tabular}{l|l}
\hline Interventions & Examples \\
\hline Individual staff & Training in key clinical processes \\
\cline { 2 - 2 } & Feedback on performance \\
\hline \multirow{2}{*}{ Task interventions } & Standardisation and simplification of processes \\
\cline { 2 - 2 } Team standardisation and & Automation of key processes \\
\cline { 2 - 2 } specification & Improved design and availability of equipment \\
\hline \multirow{2}{*}{ Working conditions } & Structured handover \\
\hline & Formalising roles and responsibilities \\
\hline & Clarity of leadership and followership \\
\hline & Organisation of ward care \\
\hline Organisational interventions & Improved lighting \\
\hline & Reduction of noise and disturbance \\
\hline & Improved work station design \\
\hline & Improved levels and organisation of staffing \\
\hline & $\begin{array}{l}\text { Creation of new posts to improve coordination of care } \\
\text { for patients }\end{array}$ \\
\hline
\end{tabular}

also point to the means of intervention and different ways of optimising the healthcare system. For instance Pascale Carayon's systems engineering approach to patient safety emphasizes interactions between people and their environment that contribute to performance, safety and health, quality of working life, and the goods or services produced (Carayon et al. 2006) (Table 6.2)

Examples of system improvements which have, amongst other objectives, had important impacts on safety include:

- The introduction of bar coding and decision support in blood collection and transfusion (Murphy et al. 2009).

- The improvement of communication and handover along the surgical pathway (de Vries et al. 2010)

- Using information technology to reduce medication errors (Bates 2000; Avery et al. 2012)

- The use of daily goals sheets to improve the reliability of ward care (Pronovost et al. 2003)

The improvement of healthcare systems is a massive topic and there are countless examples of analyses and, to a lesser extent, interventions that are within this tradition. We cannot describe these in detail and in any case they are extensively discussed elsewhere (Carayon 2011). Systems engineering, human factors and associated disciplines are not restricted to optimisation approaches in that risk control, monitoring, adaptation and recovery are sometimes considered. However we suggest that the primary drive and focus is optimisation of the healthcare system. 


\section{Strategy III: Risk Control}

The next strategy and associated family of interventions is quite different form the optimisation approaches discussed above. In many industries safety is achieved by avoiding taking unnecessary risks or placing restrictions on the conditions of operation. In contrast healthcare seldom imposes limits on either professional autonomy or productivity even when safety is severely compromised. Risk control may seem to provide the answer to all risks, but avoiding risk sometimes means losing out on the potential gain that taking the risk may have allowed. Increasing risk regulation in hospitals can lead to avoidance of treating higher risk conditions, in favour of patients presenting with lower risk (McGivern and Fischer 2012). Avoidance of risk is not necessarily a good option for patients either as there are many circumstances in which clear-sightedly making a risky choice is entirely reasonable. However risk control does not aim to prevent a considered, if risky, decision but to improve the chances of a good outcome once the decision has been taken.

Risk control is widely used in other high-risk industries. The safety systems in nuclear and other facilities include numerous features which will stop the process if conditions become potentially unsafe. Commercial aviation uses a similar approach in many circumstances. For example, a storm in Miami will result in all flights to Miami grounded at their departure airport or diverted to others airports. Safety cases, the process by which potential oil and other installations are assessed, are almost unknown in healthcare. New clinical facilities are opened, or indeed closed, largely on grounds of need and cost without any formal risk assessments. Safety cases are designed to offer formal assurance and assessment that the facility can be run safely but also set out the conditions under which this can occur and building in procedures or automation to restrict activity when necessary. These are all examples of risk control by placing limits or restrictions on productive activity in the interests of safety (Table 6.3).

Table 6.3 Risk control

\begin{tabular}{l|l}
\hline Interventions & Examples \\
\hline \multirow{2}{*}{ Withdraw services } & Close facilities if evidence of serious safety concerns \\
\cline { 2 - 2 } & $\begin{array}{l}\text { Close facilities temporarily while safety assessments are } \\
\text { carried out }\end{array}$ \\
\hline \multirow{2}{*}{ Reduce demand } & Reduce overall demand \\
\cline { 2 - 2 } & Reduce patient flow either temporarily or permanently \\
\hline Place restrictions on services & Restrict services either temporarily or permanently \\
\hline Place restrictions on individuals & Define 'no-go' conditions for investigations and treatments \\
\cline { 2 - 2 } or conditions of operation & $\begin{array}{l}\text { Withdraw or restrict individual members of staff either } \\
\text { temporarily or permanently }\end{array}$ \\
\hline Prioritisation & $\begin{array}{l}\text { Select and emphasise safety critical standards while } \\
\text { allowing some reduction of other work, either temporarily } \\
\text { or permanently }\end{array}$ \\
\hline
\end{tabular}


Healthcare does contain examples of risk control but these are seldom discussed in the context of patient safety. For instance in 2013 the medical director of the British NHS decided to temporarily close a major cardiac surgery unit because there were indications of excess mortality. He made it clear that this was just a precaution. After a few weeks, following further investigations, the unit reopened. This was seen as a very unusual intervention which caused considerable uproar. Yet, in aviation, airports are closed as soon as any substantial risk is identified.

Risk control can also be achieved by severely limiting the circumstances in which a unit can operate. Consider, for example, the way that the Australian healthcare system places very strict limits of what some clinics are allowed to do (New South Wales Government Private Facilities 2007). Some clinics are only authorised to work in a very specific medical area, and are staffed and equipped accordingly. Within this area, the facility must accept patients and deliver safe care; outside this area, the facility is not allowed to deliver care and must transfer all patients to a competent facility.

Risk control can include withdrawing services or even closing facilities when they have become dangerous. However the main thrust of this approach is to restrict the conditions in which investigations or treatment can be given. There are, for instance, very strict regulations governing the provision of radiotherapy but almost no restrictions on the conditions in which a surgical operation can go ahead. We believe that much more consideration should be given to the control of risk to protect both patients and staff from engaging in unnecessarily risky activities.

\section{Strategy IV: Monitoring, Adaptation and Response}

Safety is achieved partly by attempting to reduce errors but also by actively managing the problems and deviations that inevitably occur. Once we accept that errors and failures occur frequently in any system then we see the need to develop methods of monitoring, adapting and responding and recovering from failure. Adapting and responding to problems happens all the time in healthcare and is as relevant to managers as to frontline staff. Managers in particularly are constantly 'firefighting' and resolving problems, but this tends to be done on an ad hoc individual basis. The question we address here is whether these often improvised adaptations can evolve to become formal safety strategies in the sense of actively building such capacity into healthcare systems. Ideally senior clinicians and managers would maintain safety at a good level by playing on a palette of known and practiced organisational and cultural adjustments.

Adapting and responding is much more important in deep sea fishing than on an assembly line but all work requires this capacity to some degree. Being on the lookout for problems, adapting and working around difficulties is part and parcel of all jobs. In high risk industries such as healthcare the pattern is the same but the stakes are much higher and the capacity for rapid response and recovery may literally be a matter of life and death. This family of interventions is paradoxically the most used in daily work in healthcare but not properly developed as a strategic reality in patient safety. 
The broad capacity of adapting and responding has been discussed extensively in the safety literature and made the cornerstone of some approaches to safety such as resilience engineering (Hollnagel et al. 2007). The term resilience is used in very different ways (Macrae 2014), sometimes very broadly in an attempt to describe and articulate the qualities of a safe organisation and sometimes in a more restricted sense of a capacity to adapt and recover from extreme or unusual circumstances. We believe that resilience is an important concept that needs serious consideration and further research and exploration in practice. However to avoid potential confusion we use the more everyday terms of monitoring, adaptation and recovery to denote occasions where or hazards or failures have been detected and are being actively managed or corrected.

We will describe a number of interventions associated with this approach in the following chapters and will just give some brief examples here (Table 6.4). An emphasis on the open discussion of error and system failures by senior leaders is enormously important in fostering a willingness to speak up and intervene if a patient is at risk. Clinical teams use many adaptive mechanisms, both formal and informal, to manage safety on a day to day basis. Anaesthetists for instance have a standard repertoire of prepared emergency routines which are called upon in certain situations. These routines are only seldom used and are deliberately honed and standardised so that they can be adhered to at times of considerable stress. At an organisational level we could see preparations for a possible infection outbreak in a similar way (Zingg et al. 2015). Briefings and debriefings can be used by ward staff, operating theatre teams and healthcare managers to monitor day to day threats to safety. For example, briefings carried out by operating theatre teams provide an opportunity to identify and resolve equipment, staffing, theatre list order issues before a case starts. Debriefings carried out at the end of the theatre list support reflective learning on what went well and what could be done better tomorrow.

Table 6.4 Improve capacity for monitoring, adaptation and response

\begin{tabular}{|c|c|}
\hline Interventions & Examples \\
\hline \multirow[t]{2}{*}{ Improve safety culture } & Patient and family engagement \\
\hline & Culture of openness about error and failure \\
\hline \multirow{4}{*}{$\begin{array}{l}\text { Monitoring, adaptation and response in } \\
\text { clinical teams }\end{array}$} & Rapid response to deterioration \\
\hline & $\begin{array}{l}\text { Develop emergency response systems and } \\
\text { routines }\end{array}$ \\
\hline & $\begin{array}{l}\text { Develop team cross checking and safety } \\
\text { monitoring }\end{array}$ \\
\hline & $\begin{array}{l}\text { Building briefing and anticipation into clinical } \\
\text { routines }\end{array}$ \\
\hline \multirow[t]{2}{*}{$\begin{array}{l}\text { Improve management of organisational } \\
\text { pressures and priorities }\end{array}$} & $\begin{array}{l}\text { Develop methods of predicting times of staff } \\
\text { shortage and other pressures }\end{array}$ \\
\hline & $\begin{array}{l}\text { Improve managerial capacity to deal with } \\
\text { dangerous situations }\end{array}$ \\
\hline \multirow[t]{2}{*}{ Regulatory compromises and adaptation } & Negotiate time to move to new standards \\
\hline & Actively manage safety during time of transition \\
\hline
\end{tabular}


Increasingly, briefings and debriefings are being introduced in other healthcare domains such as safeguarding adults and mental health teams (Vincent et al. 2013).

\section{Strategy V: Mitigation}

Mitigation is the action of reducing the severity, seriousness, or painfulness of some event. This strategy accepts that patients and indeed staff will sometimes be seriously affected or harmed during their healthcare and, critically, that the organisation concerned then has a responsibility to mitigate that harm. In particular we believe that organisations need to have effective systems in place to support patients, carers and staff in the aftermath of serious failures and harm. This is perhaps the most neglected aspect of patient safety (Table 6.5).

Accepting risk in healthcare seems at first glance to either be an admission of defeat or a cynical disregard for patients. However this strategy is rather more subtle and more important than one might think both at the clinical and organisational level. Planning for these occasions can seem to indicate a resigned acceptance of harm; in reality planning for recovery is humanitarian and necessary. A complete approach to safety must include the mitigation of harm, although managing complaints and litigation should not dominate attempts to improve safety.

Organisations of all kinds must insure against risk, deal with complaints and litigation, and manage the media and regulatory response Organisations must also make insurance arrangements for compensation to injured patients. At a national level countries develop medical insurance systems, such as no-fault compensation, to support patients who have been harmed. In most countries, the challenge of addressing error in medicine demands a thorough reconsideration of the legal mechanisms currently used to deal with error and harm in health care.

The basic needs of injured patients have been understood for 20 years (Vincent et al. 1994). We would all, in varying degrees, like an apology, an explanation, to know that steps had been taken to prevent recurrence and potentially financial and

Table 6.5 Mitigation

\begin{tabular}{l|l}
\hline Interventions & Examples \\
\hline \multirow{3}{*}{ Support for patients and carers } & Rapid response and clear communication \\
\cline { 2 - 2 } & Designated follow up, psychological and physical support \\
\cline { 2 - 2 } Support for staff & $\begin{array}{l}\text { Plan clinical services for response to known } \\
\text { complications }\end{array}$ \\
\hline \multirow{2}{*}{$\begin{array}{l}\text { Financial, legal and media } \\
\text { response }\end{array}$} & Peer to peer support programmes \\
\cline { 2 - 2 } & Temporary relief from clinical duties \\
\hline & Provision of longer term support \\
\cline { 2 - 2 } & $\begin{array}{l}\text { Insurance of organisation } \\
\text { claims }\end{array}$ \\
\cline { 2 - 2 } & Capacity for rapid and proactive media response \\
\hline
\end{tabular}


practical assistance. Many patients experience errors during their treatment, whether they realise it or not, and some are harmed by healthcare. The harm may be minor, involving only inconvenience or discomfort, but can involve serious disability or death. Almost all bad outcomes will have some psychological consequences for both patients and staff, ranging from minor worry and distress through to depression and even despair. The experiences of these people tend not to be fully appreciated, and yet understanding the impact of such injuries is a prerequisite of providing useful and effective help (Vincent 2010). Healthcare organisations generally have extremely limited services to support either patients or staff in the aftermath of adverse events.

We know too that staff suffer a variety of consequences from being the 'second victim' as Albert Wu eloquently expressed it, not implying that the experiences of staff were necessarily comparable to those of injured patients (Wu 2000). We should also consider that a member of staff who has been seriously affected may well be performing poorly and be a risk to future patients; this again is rarely addressed. There are a few pioneering examples of programmes of support for both patients and staff (Van Pelt 2008) but this is an area of safety management which needs substantial development. We consider that this should be a core safety strategy; planning for recovery should include this core humanitarian element as well as managing risk and reputation.

\section{Innovation}

Safety problems are sometimes resolved because of the introduction of a completely new way of investigating or treating an illness or a new way of providing and organising care. Innovation in healthcare can take many forms, ranging from drug therapies, surgical procedures, devices, and tests, through to new forms of health professional training, patient education, management, financing and service delivery models. These innovations generally aim to provide better or more efficient care for patients, but safety may also be improved as a virtuous side effect of the action

Healthcare is remarkable in the breadth and pace of innovation which both improves safety and, as we have argued earlier, also changes the boundaries of what is acceptable and so creates new safety problems. The pace of innovation is such that medical knowledge dates extremely rapidly. In 2007, the median time before medical knowledge needed significant updating was only 5 years; $23 \%$ of systematic reviews needed updating within 2 years and $15 \%$ within 1 year (Shojania et al. 2007). According to both the United Kingdom National Institute of Clinical Excellence and the American Heart Association most recommendations and treatment guidelines need substantial adjustment every 5 years (Alderson et al. 2014; Neuman et al. 2014).

Many innovations in diagnosis and treatment have had a major positive impact on safety. For example safety in anaesthesia has improved about ten-fold over the last past 20 years, with the consensus being that the greatest safety gains have arisen 
from the introduction of new drugs and techniques for monitoring and for regional and ambulatory anaesthesia (Lanier 2006). The rapid introduction and spread of laparoscopic surgery has reduced length of stay, led to more rapid recovery and reduced risk of infection and other problems (Shabanzadeh and Sørensen 2012).

Safety may also be improved indirectly through the reorganisation of the healthcare system, particularly through realignment to a more patient centred vision. Many failures of care in community settings are due to failures of coordination and communication between agencies and across different parts of the system. One aspect of the 'burden of treatment' (Mair and May 2014) experienced by patients and families is that they have to organise and coordinate their own care to compensate for the failures of the healthcare system. If we succeed in developing more integrated systems of care across settings and populations these problems should reduce. Patients will be safer and experience fewer failures although the changes are not specifically targeted at safety.

Innovation is not really a safety strategy, although safety interventions may be innovative. New treatments or technologies are usually targeted at wider benefits for patients with reduction of risk being a secondary benefit. More importantly in this context 'innovation' cannot be deployed as a strategy in the same way as optimisation, control and recovery. Our imaginary chief executive with a 3-5 year time horizon cannot rely on innovation to solve safety problems but must nevertheless to alert to new developments that may change the nature of the problems that they are facing.

To sum up, innovation is a good example of a double-edged tool for safety. On the one hand, it is a critical determinant and means (perhaps the most significant) of improving safety in the long term. Innovation may also introduces new risks as well as resolving old ones particularly in the short term during the period of transition and disruption (Dixon-Woods et al. 2011). Safety may be degraded in the short term due to rapid diffusion of insufficiently tested new methods and uncontrolled individual experimentation.

\section{Selection and Customisation of Strategies to Clinical Context}

We hope that the delineation of the five strategies and their associated interventions is useful as a way of thinking through the approaches that might be taken to manage risk in any particular healthcare environment. These very broad strategies are seldom explicitly distinguished and some safety programmes unwittingly combine several types of strategy with somewhat different objectives. We believe that many situations do require a combination of different approaches but that it needs to be clear how and why each strategy is deployed (Fig. 6.1). We also need to consider how these strategies and associated interventions might be combined and in what proportions. Each clinical environment brings its own challenges and requires a different combination. We have set out three broad models of clinical work to illustrate this and others may need to be articulated. The management of risk in the community for instance in highly distributed health and social care systems may require a different kind of approach. 


\section{Analysis, context and strategies}

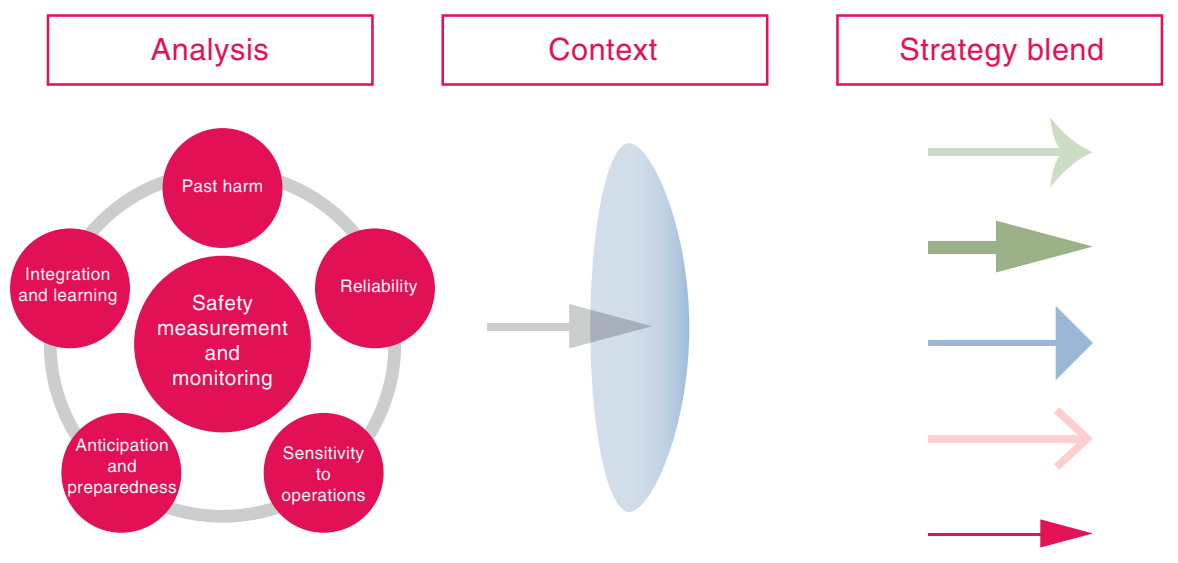

Fig. 6.1 Analysis, context and strategies

The following chapters begin to explore these ideas in more detail by providing examples of safety strategies in different settings. We can however illustrate the general idea which is that after an initial stage of diagnosis of the safety problem, illustrated by our approach to safety measurement and monitoring, the 'lens' of the clinical context will inform the particular strategy blend (see Fig. 6.1). In settings where care can be precisely defined and delineated strategies to control exposure to risk and maintain standards will predominate, hopefully accompanied by concurrent strategies to improve working conditions and support staff. In contrast in more fluid and dynamic environment strategies to improve monitoring and adaptation may be more to the fore, although all environments require a solid procedural underpinning. The next three chapters develop and illustrate these ideas in the context of hospital, home and primary care. 


\section{Key Points}

- We outline a portfolio of five strategies for improving safety in healthcare each associated with a family of interventions:

- Safety as best practice: Improving clinical processes and standards

- Improving healthcare processes and system: Intervening to support individuals and teams, improve working conditions and organisational practices

- Risk control: placing restrictions on performance, demand or working conditions

- Improving capacity for monitoring, adaptation and response.

- Mitigation: Planning for potential harm and recovery.

- Safety problems are sometimes resolved because of the introduction of a completely new way of investigating or treating an illness. These innovations generally aim to provide better or more efficient care for patients, but safety may be improved as a virtuous side effect of the innovation.

- In settings where care can be precisely delineated strategies to control exposure to risk and maintain standards will predominate. In contrast in more fluid and dynamic environment strategies to improve monitoring adaptation may be more to the fore, although all environments require a solid procedural underpinning.

- Each clinical environment brings its own challenges and requires a different combination of strategies. The management of risk in the community for instance in highly distributed health and social care systems may require a different kind of approach.

Open Access This chapter is distributed under the terms of the Creative Commons Attribution Noncommercial License, which permits any noncommercial use, distribution, and reproduction in any medium, provided the original author(s) and source are credited.

\section{References}

Alderson LJ, Alderson P, Tan T (2014) Median life span of a cohort of National Institute for Health and Care Excellence clinical guidelines was about 60 months. J Clin Epidemiol 67(1):52-55

Avery AJ, Rodgers S, Cantrill JA, Armstrong S, Cresswell K, Eden M, Elliott RA, Howard R, Kendrick D, Morris CJ, Prescott RJ, Swanwick G, Franklin M, Putman K, Boyd M, Sheikh A (2012) A pharmacist-led information technology intervention for medication errors (PINCER): a multicentre, cluster randomised, controlled trial and cost-effectiveness analysis. Lancet 379(9823):1310-1319

Bates DW (2000) Using information technology to reduce rates of medication errors in hospitals. Br Med J 320(7237):788

Carayon P (ed) (2011) Handbook of human factors and ergonomics in health care and patient safety. CRC Press, New York 
Carayon P, Hundt AS, Karsh BT, Gurses AP, Alvarado CJ, Smith M, Brennan PF (2006) Work system design for patient safety: the SEIPS model. Qual Saf Health Care 15(suppl 1):i50-i58

de Vries EN, Prins HA, Crolla RM, den Outer AJ, van Andel G, van Helden SH, Schlack WS, van Putten MA, Gouma DJ, Dijkgraaf MGW, Smorenburg SM, Boermeester MA (2010) Effect of a comprehensive surgical safety system on patient outcomes. N Engl J Med 363(20):1928-1937

Dixon-Woods M, Amalberti R, Goodman S, Bergman B, Glasziou P (2011) Problems and promises of innovation: why healthcare needs to rethink its love/hate relationship with the new. BMJ Qual Saf 20(suppl):i47-i51

Hollnagel E, Woods DD, Leveson N (eds) (2007) Resilience engineering: concepts and precepts. Ashgate Publishing, Guildford

Lanier WL (2006) A three-decade perspective on anesthesia safety. Am Surg 72(11):985-989

Macrae C (2014) Close calls: managing risk and resilience in airline flight safety. Palgrave Macmillan, London

Mair FS, May CR (2014) Thinking about the burden of treatment. BMC Health Serv Res 14:281

McGivern G, Fischer MD (2012) Reactivity and reactions to regulatory transparency in medicine, psychotherapy and counselling. Soc Sci Med 74(3):289-296

Murphy MF, Staves J, Davies A, Fraser E, Parker R, Cripps B, Kay J, Vincent C (2009) How do we approach a major change program using the example of the development, evaluation, and implementation of an electronic transfusion management system? Transfusion 49(5): 829-837

Neuman MD, Goldstein JN, Cirullo MA, Schwartz JS (2014) Durability of class I American College of Cardiology and American Heart Association clinical practice guideline recommendations. JAMA 311(20):2092-2100

New South Wales Government Private Facilities Act (2007) http://www.health.nsw.gov.au/hospitals/privatehealth/pages/default.aspx. Accessed 2 Aug 2015

Pronovost P, Berenholtz S, Dorman T, Lipsett PA, Simmonds T, Haraden C (2003) Improving communication in the ICU using daily goals. J Crit Care 18(2):71-75

Pronovost PJ, Berenholtz SM, Needham DM (2008) Translating evidence into practice: a model for large scale knowledge translation. BMJ 337:a1714

Shabanzadeh DM, Sørensen LT (2012) Laparoscopic surgery compared with open surgery decreases surgical site infection in obese patients: a systematic review and meta-analysis. Ann Surg 256(6):934-945

Shekelle PG, Pronovost PJ, Wachter RM, Taylor SL, Dy SM, Foy R, Hempel S, McDonald KM, Ovretveit J, Rubenstein LV, Adams AS, Angood PB, Bates DW, Bickman L, Carayon P, Donaldson L, Duan N, Farley DO, Greenhalgh T, Haughom J, Lake ET, Lilford R, Lohr KN, Meyer GS, Miller MR, Neuhauser DV, Ryan G, Saint S, Shojania KG, Shortell SM, Stevens DP, Walshe K (2011) Advancing the science of patient safety. Ann Intern Med 154(10):693-696

Shojania KG, Sampson M, Ansari MT, Ji J, Doucette S, Moher D (2007) How quickly do systematic reviews go out of date? A survival analysis. Ann Intern Med 147(4):224-233

Van Pelt F (2008) Peer support: healthcare professionals supporting each other after adverse medical events. Qual Saf Health Care 17(4):249-252

Vincent C (2010) Patient safety, 2nd edn. Wiley Blackwell, Oxford

Vincent C, Phillips A, Young M (1994) Why do people sue doctors? A study of patients and relatives taking legal action. Lancet 343(8913):1609-1613

Vincent C, Taylor-Adams S, Stanhope N (1998) Framework for analysing risk and safety in clinical medicine. Br Med J 316(7138):1154-1157

Vincent C, Burnett S, Carthey J (2013) The measurement and monitoring of safety. The Health Foundation, London

Wu A (2000) Medical error: the second victim. Br Med J 320:726-727

Zingg W, Holmes A, Dettenkofer M, Goetting T, Secci F, Clack L, Allegranzi B, Magiorakos AP, Pittet D (2015) Hospital organisation, management, and structure for prevention of health-careassociated infection: a systematic review and expert consensus. Lancet Infect Dis 15:212-224 